\title{
Analysis of the sakacin P gene cluster from Lactobacillus sake Lb674 and its expression in sakacin-negative $\mathbf{L b}$. sake strains
}

\author{
Kathrin Hühne, ${ }^{1}$ Lars Axelsson, ${ }^{2}$ Askild Holck ${ }^{2}$ and Lothar Kröckel ${ }^{1}$ \\ Author for correspondence: Lothar Kröckel. Tel: +499221 803 234. Fax: +49 9221803331. \\ e-mail: 100440.72@compuserve.com
}

\begin{abstract}
1 Institute for Microbiology and Toxicology, Federal Center of Meat Research, E.-C.-Baumann-Strape 20, D-95326 Kulmbach, Germany

2 MATFORSK, Norwegian Food Research Institute, Osloveien 1, N-1430 Ås, Norway
\end{abstract}

\begin{abstract}
Sakacin P is a small, heat-stable, ribosomally synthesized peptide produced by certain strains of Lactobacillus sake. It inhibits the growth of several Grampositive bacteria, including Listeria monocytogenes. A $7.6 \mathrm{~kb}$ chromosomal DNA fragment from $L b$. sake $L b 674$ encompassing all genes responsible for sakacin $P$ production and immunity was sequenced and introduced into $L b$. sake strains Lb790 and Lb706X which are bacteriocin-negative and sensitive to sakacin $P$. The transformants produced sakacin $P$ in comparable amounts to the parental strain, Lb674. The sakacin $P$ gene cluster comprised six consecutive genes: sppK, sppR, sppA, spiA, sppT and sppE, all transcribed in the same direction. The deduced proteins SppK and SppR resembled the histidine kinase and response regulator proteins of bacterial two-component signal transducing systems of the AgrB/AgrA-type. The genes sppA and spiA encoded the sakacin $P$ preprotein and the putative immunity protein, respectively. The predicted proteins SppT and SppE showed strong similarities to the proposed transport proteins of several other bacteriocins and to proteins implicated in the signal-sequence-independent export of Escherichia coli haemolysin A. Deletion and frameshift mutation analyses showed that sppK, sppT and sppE were essential for sakacin P production in Lb706X. The putative SpiA peptide was shown to be involved in immunity to sakacin $P$. Analogues of SppR and spiA were found on the chromosomes of $L b$. sake Lb706X and Lb790, indicating the presence of an incomplete spp gene cluster in these strains.
\end{abstract}

Keywords: Lactobacillus sake, sakacin P, spp gene cluster, bacteriocin, two-component signal-transducing system

\section{INTRODUCTION}

Sakacin $\mathrm{P}$ is an anti-listerial peptide produced by Lactobacillus sake strains Lb674 and LTH673 (Holck et al., 1994; Tichaczek et al., 1994). It belongs to a group of antimicrobial proteinaceous compounds, known as bacteriocins, which are secreted by many Gram-positive bacteria. Bacteriocins usually inhibit the growth of species closely related to the producer strain but may also be active against less related bacteria. Some bacteriocins from lactic acid bacteria (LAB) are of interest to the food

Abbreviations: HPK, histidine protein kinase; LAB, lactic acid bacteria; RR, response regulator protein.

The EMBL accession number for the nucleotide sequence reported in this paper is $\mathbf{Z 4 8 5 4 2 .}$ industry because of their potential use in inhibiting the growth of food spoilage microorganisms and pathogens such as Listeria monocytogenes (Hillier \& Davidson, 1991; Vandenbergh, 1993).

The bacteriocins of LAB differ in structure, size and mode of action. The small, peptide-like bacteriocins are divided into two classes (Klaenhammer, 1993). Class I comprises the lantibiotics which contain the unusual amino acids lanthionine and $\beta$-methyllanthionine (Schnell et al., 1988). The lantibiotic nisin produced by Lactococcus lactis subsp. lactis is used in many countries for the preservation of milk products and other foods. Class II bacteriocins comprise small, heat-stable proteins which contain no modified amino acids. Examples of class II bacteriocins are sakacins $A, P$ and 674 , which are produced by different meat strains of Lb. sake (Holck et al., 1992, 1994; Tichaczek et al., 1992), pediocin PA-1 from Pediococcus 
acidilactici (Henderson et al., 1992), leucocin A-UAL 187 from Leuconostoc gelidum (Hastings et al., 1991), mesentericin Y105 from Leuconostoc mesenteroides Y105 (Fremaux et al., 1995), carnobacteriocins B2 and BM1 from Carnobacterium piscicola LV17B (Quadri et al., 1994), lactococcin A from Lc. lactis (Holo et al., 1991), and plantaricin A from Lactobacillus plantarum (Nissen-Meyer et al., 1993). Class I and class II bacteriocins are synthesized as precursor proteins. Their $\mathrm{N}$-terminal leader sequence is cleaved before the mature product is released from the cell. It has emerged that sakacins $\mathrm{P}$ and 674 are identical (see below) and are closely related to pediocin PA-1 with regard to the mature peptides (67\% amino acid identity), whereas the relation to sakacin $\mathrm{A}$ is less pronounced $33 \%$ amino acid identity). Sakacin $P$, together with pediocin PA-1, sakacin A and other bacteriocins, contains the Nterminal sequence motif YGNGV and is therefore considered to belong to a sub-family of class II bacteriocins (Klaenhammer, 1993).

Besides the bacteriocin structural genes, a number of additional genetic determinants are involved in bacteriocin production. These genes are often located in the vicinity of the bacteriocin genes and encode proteins involved in the regulation of bacteriocin production, in processing of the prepeptide, in secretion of the mature bacteriocin and in host immunity. Small genes are frequently found immediately downstream of the bacteriocin structural gene and these have in some cases been shown to encode the immunity factor (Axelsson \& Holck, 1995; Quadri et al., 1995; van Belkum et al., 1991; van Belkum \& Stiles, 1995; Venema et al., 1995). In the plantaricin A system of $L b$. plantarum $\mathrm{C} 11$, the reading frames $p \ln B, p \ln C$ and $p \ln D$ encode proteins that are homologous to members of the bacterial two-component regulatory systems (Diep et al., 1994). In the vicinity of the pediocin PA-1 and lactococcin A structural genes, ORFs were identified whose predicted proteins belong to the HlyB family of ATP-dependent membrane translocators (Marugg et al., 1992; Stoddard et al., 1992). In the vicinity of the sakacin A structural gene, the genes of both an AgrB/AgrA-like bacterial two-component signal transducing system and of a HlyB/HlyD-like transport system were identified (Axelsson \& Holck, 1995).

Recently, we reported the purification of sakacin 674 from Lb. sake Lb674, and the cloning and sequencing of its chromosomally located structural gene sakR (Holck et al., 1994). Tichaczek et al. (1994) reported the nucleotide sequence of the sakacin P structural gene from $L b$. sake LTH673 which is identical to sakacin 674 . The strains LTH673 and Lb674 were isolated from different sources and can be distinguished from each other by their plasmid content. To avoid further confusion, the bacteriocin produced by $L b$. sake Lb674 is henceforth referred to as 'sakacin P'. Also, to avoid confusion with the genes involved in sakacin A production (sap genes) by Lb. sake Lb706 (Axelsson \& Holck, 1995), the genes associated with sakacin $\mathrm{P}$ production are named using the prefix ' $s p p$ '.

Most of the bacteriocins described to date are derived from lactobacilli that are not typically found in meat. Strains of L $b$. sake and Lactobacillus curvatus are important starter cultures in meat fermentations. Because they are very competitive at lower ripening temperatures they are frequently used for the production of traditional raw fermented sausages. Lactobacilli used for raw sausage production normally do not produce bacteriocin, although such a trait could improve the microbiological safety and stability of the meat products. We are therefore interested in finding an expression system for sakacin $\mathrm{P}$, which would allow improvement of established meat starter cultures, especially with respect to their inhibitory potential against Li. monocytogenes. In this study, we defined a DNA fragment containing all information necessary for expression of sakacin $\mathrm{P}$ in sakacin-negative $L b$. sake host strains. The nucleotide sequence of this fragment was determined and mutation/deletion analyses were performed to investigate the role of the individual genes in bacteriocin production.

\section{METHODS}

Bacterial strains, plasmids and growth conditions. Bacterial strains and plasmids used in this study are shown in Table 1. Lb. sake $\mathrm{Lb} 790$ is a bacteriocin-negative and sakacin-P sensitive strain. $L b$. sake Lb706X is a plasmid-free derivative of the sakacin A producer Lb706. Since the sakacin A gene cluster is located on one of the plasmids, Lb706X has lost both production of and immunity to sakacin A. The Lactobacillus strains used in this study were isolated from different meat sources and are not related to each other in any way other than being identified as Lb. sake. The Lactobacillus strains were cultured in MRS broth (Merck), routinely at $25^{\circ} \mathrm{C}$, but at $30^{\circ} \mathrm{C}$ when used in electrotransformation experiments. Listeria innocua Li1 was grown in Standard-I medium (Merck) at $37^{\circ} \mathrm{C}$. Escherichia coli strains were propagated in LB broth (Sambrook et al., 1989) at $37^{\circ} \mathrm{C}$. Solid media were prepared by adding $1 \cdot 2 \%(\mathrm{w} / \mathrm{v})$ agar to the broth. E. coli and Lactobacillus transformants were selected and cultured in the presence of antibiotics at the following concentrations: ampicillin, $100 \mu \mathrm{g} \mathrm{ml}^{-1}$; erythromycin, $10 \mu \mathrm{g}$ $\mathrm{ml}^{-1}$ for lactic acid bacteria and $200 \mu \mathrm{g} \mathrm{ml}^{-1}$ for E. coli.

Bacteriocin activity and immunity. Bacteriocin production and immunity were determined by using a well diffusion assay as described by Schillinger \& Lücke (1989). Controls were performed with culture supernatants from bacteriocin-producing $\left(\mathrm{Bac}^{+}\right)$and non-producing $\left(\mathrm{Bac}^{-}\right)$strains, and with trypsin-digested $\mathrm{Bac}^{+}$supernatants. Li. innocua Li1 was used as an indicator strain to represent the antagonistic activity of sakacin $\mathrm{P}$ against $\mathrm{Li}$. monocytogenes. To avoid inhibition of the indicator strain by erythromycin, the antibiotic was removed from the bacteriocin-containing culture supernatants by pelleting the protein in the presence of $40 \%(\mathrm{w} / \mathrm{v})$ ammonium sulfate, resuspending the pellet in $\mathrm{H}_{2} \mathrm{O}$ and passing it through a Sephadex PD-10 column (Pharmacia). The antagonistic products in the culture supernatants of $L b$. sake transformants were tested for heat resistance, sensitivity to trypsin and inhibitory spectra to confirm their identity with sakacin $P$. The immunity of $L b$. sake transformants was tested against high purity sakacin $\mathrm{P}$, which was obtained from Lb. sake Lb674 as described previously (Holck et al., 1994).

Molecular cloning. Plasmid DNA from E. coli cells was isolated by the alkaline lysis method according to Sambrook et al. (1989) and from lactobacilli as described previously (Axelsson et al., 
Table 1. Bacterial strains and plasmids

\begin{tabular}{|c|c|c|}
\hline Strain or plasmid & Description* & Source or reference \\
\hline \multicolumn{3}{|l|}{ Strains } \\
\hline \multicolumn{3}{|l|}{ Lactobacillus sake } \\
\hline Lb674 & Wild-type strain; Spp ${ }^{+}, \mathrm{Imm}^{+}$ & Holck et al. (1994) \\
\hline Lb790 & $\begin{array}{l}\text { Host strain for pLPV111 and derivatives; sensitive to sakacin } \\
\text { P, Spp } \text { Imm }^{-}\end{array}$ & Schillinger \& Lücke (1989) \\
\hline Lb706X & $\begin{array}{l}\text { Host strain for pLPV111 and derivatives; sensitive to sakacin } \\
\mathrm{P}, \mathrm{SPP}^{-}, \mathrm{Imm}^{-}\end{array}$ & Axelsson et al. (1993) \\
\hline Lb790/111 & $\begin{array}{l}\text { Lb790 carrying pLPV111, indicator strain; sensitive to } \\
\text { sakacin P, Spp } \\
-1 \mathrm{Imm}^{-}, \mathrm{Em}^{\mathrm{r}}\end{array}$ & This study \\
\hline Listeria innocua Li1 & Indicator strain; sensitive to sakacin $\mathrm{P}, \mathrm{SpP}^{-}, \mathrm{Imm}^{-}$ & This study \\
\hline \multicolumn{3}{|l|}{ Eschericbia coli } \\
\hline $\mathrm{DH} 5 \alpha$ & 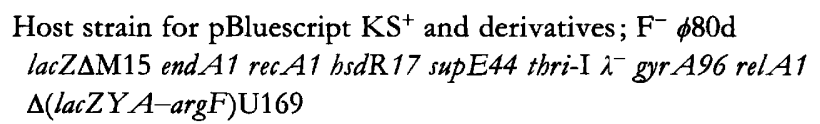 & Gibco BRL \\
\hline JM105 & $\begin{array}{l}\text { Host strain for pLPV111 and derivatives; thi rpsL end } A \\
s b c B 15 \text { bsdR4 } \Delta(\text { lac-pro } A B) / \mathrm{F}^{\prime}\left[\operatorname{traD} 36 \text { pro } A B \text { lac }{ }^{\mathrm{q}} \text { lacZ } \mathrm{M} 15\right]\end{array}$ & Pharmacia \\
\hline \multicolumn{3}{|l|}{ Plasmids } \\
\hline pGEM-7Zf $(+)$ & $3.0 \mathrm{~kb}$ cloning vector; replicates in E. coli, $\mathrm{Ap}^{\mathrm{r}}, \operatorname{lac} Z$ & Promega \\
\hline pBluescript $\mathrm{KS}^{+}$ & $3.0 \mathrm{~kb}$ cloning vector; replicates in $E$. coli, $\mathrm{Ap}^{\mathrm{r}}$, lac $\mathrm{Z}$ & Stratagene \\
\hline pLPV111 & $\begin{array}{l}4.2 \mathrm{~kb} E . \text { coli } / L b . \text { plantarum } / L b . \text { sake shuttle vector; } \mathrm{Em}^{\mathrm{r}} \text {, } \\
\text { lacZ }\end{array}$ & Axelsson \& Holck (1995) \\
\hline \multicolumn{3}{|c|}{ pGEM-7Zf $(+)$ derivative $\left(A p^{r}\right)$} \\
\hline pBLS1 & $\begin{array}{l}3.9 \mathrm{~kb} C l a \mathrm{I} / \text { EcoRI fragment from Lb. sake Lb674 DNA; } \\
s p p \mathrm{R}^{+} A^{+} T^{+} s p i A^{+}\end{array}$ & Holck et al. (1994) \\
\hline \multicolumn{3}{|c|}{$\mathrm{pBluescript} \mathrm{KS}^{+}$derivatives $\left(\mathrm{Ap}^{\mathrm{r}}\right)$} \\
\hline pBLS2 & $\begin{array}{l}1.3 \mathrm{~kb} H p a \mathrm{II} \text { fragment from } L b . \text { sake Lb674 DNA; part of } \\
s p p K \text { gene }\end{array}$ & \multirow{9}{*}{ This study } \\
\hline pBLS3 & $\begin{array}{l}3.7 \mathrm{~kb} P v u I \text { fragment from } L b . \text { sake Lb674 DNA; part of } \\
s p p T \text { gene, } s p p E^{+}\end{array}$ & \\
\hline \multicolumn{3}{|c|}{ pLPV111 derivatives $\left(\mathrm{Em}^{\mathrm{r}}\right)$} \\
\hline pMLS114 & $\begin{array}{l}7 \cdot 6 \text { kb insert, combined inserts of } p B L S 1, p B L S 2 \text { and } \\
p B L S 3 ; s p p K^{+} R^{+} A^{+} T^{+} E^{+} s p i A^{+}\end{array}$ & \\
\hline MLS114-K & $\begin{array}{l}p M L S 114 \text { derivative with a frameshift mutation in } \operatorname{sppK}(\text { ClaI } \\
\text { site); spp } \mathrm{R}^{+} A^{+} T^{+} E^{+} \operatorname{spi} A^{+} \operatorname{sppK} 110\end{array}$ & \\
\hline pMLS114-R & 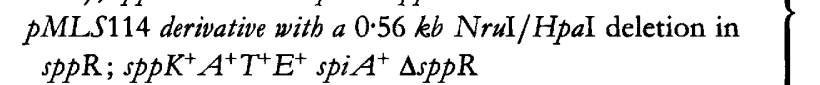 & \\
\hline pMLS114-I & $\begin{array}{l}p M L S 114 \text { derivative with a frameshift mutation in spiA } \\
\text { (Bg/II site); sppK } K^{+} \mathrm{R}^{+} A^{+} T^{+} E^{+} \text {spi } A 27\end{array}$ & \\
\hline pMLS114-T & $\begin{array}{l}p M L S 114 \text { derivative with a } 0.99 \text { kb SnaBI/Eco RV deletion; } \\
\operatorname{spp} K^{+} R^{+} A^{+} E^{+} \text {spiA }{ }^{+} \Delta s p p T\end{array}$ & \\
\hline pMLS114-E & $\begin{array}{l}p M L S 114 \text { derivative with a } 1.07 k b \text { ScaI/Xbol deletion; } \\
\text { spp } K^{+} R^{+} A^{+} T^{+} \text {spi } A^{+} \Delta s p p E\end{array}$ & \\
\hline pMLS-IP & $\begin{array}{l}0.56 \text { kb PCR fragment from } p M L S 114 ; \text { erm Lp spi } A^{+} \\
\text {AsppKR ATE }\end{array}$ & \\
\hline
\end{tabular}

*Spp, sakacin P production; Imm, immunity to sakacin P; Ap ${ }^{r}$, ampicillin resistance; $\mathrm{Em}^{\mathrm{r}}$, erythromycin resistance; erm $L p$, gene under control of the ermL promoter.

1993). Chromosomal DNA of Lb. sake Lb674 was isolated by the following method. The cells of a $150 \mathrm{ml}$ culture $\left(\mathrm{OD}_{600} 1.0\right)$ were harvested and lysed in $15 \mathrm{ml}$ lysozyme solution $(10 \mathrm{mg}$ lysozyme $\mathrm{ml}^{-1}$ in $10 \mathrm{mM}$ Tris $/ \mathrm{HCl}, 0.3 \mathrm{M}$ sucrose, $\mathrm{pH} 8.0$ ) at $37^{\circ} \mathrm{C}$ for $1 \mathrm{~h}$. The cells were collected by centrifugation and resuspended in $10 \mathrm{ml} \mathrm{NAE}$ buffer $(0.15 \mathrm{M} \mathrm{NaCl}, 0.1 \mathrm{M}$ EDTA, $\mathrm{pH} 8 \cdot 0$ ). Two millilitres of a proteinase $\mathrm{K}$ (Boehringer) solution $\left[1 \mathrm{mg}(\mathrm{ml} \mathrm{NAE})^{-1}\right]$ and $1 \mathrm{ml} 20 \%(\mathrm{w} / \mathrm{v})$ sodium dodecyl sulfate were added and the suspension was incubated for $3-4$ h at $37^{\circ} \mathrm{C}$, followed by an additional incubation step for $20 \mathrm{~min}$ at $60^{\circ} \mathrm{C}$. The DNA was extracted with phenol/chloroform/isoamyl alcohol $(24: 24: 1)$, treated with RNase and re-extracted before precipitation with ethanol.

The basic cloning techniques of Sambrook et al. (1989) were used. Restriction enzymes, T4 DNA ligase and calf intestinal 
alkaline phosphatase (from Amersham, Pharmacia and Boehringer, respectively) were used according to the suppliers' recommendations. Amplification (PCR) reactions were performed as described by Axelsson \& Holck (1995). DNA fragments were isolated from agarose gels using the USBioClean-MP kit (Amersham). Deletions/inactivations of genes were achieved by the use of available restriction sites. Frameshift mutations were introduced by linearizing plasmids at appropriate restriction sites; the ends were made blunt with a fill-in reaction using deoxynucleotide triphosphates and the Klenow fragment before ligation, recircularizing the plasmids and subsequently introducing them into the recipient strains. The desired mutations were confirmed by the absence of the restriction site used and by determining the nucleotide sequence. All manipulations were done in $E$. coli and the desired constructions were then transferred to the $L b$. sake hosts. Transformation of $L b$. sake was done by electroporation according to the protocol of Aukrust \& Blom (1992).

Plasmid constructions. Derivatives of the plasmid pMLS114, carrying the $s p p$ gene cluster were made as follows. A frameshift mutation was introduced in the ClaI site of $s p p K$ using an intermediate pLPV111 construct containing the joint pBLS2 and pBLS1 fragments. The single ClaI site was made blunt and the plasmid religated. Then the purified $N d e I-X b o I$ fragment derived from pMLS114 was added to form pMLS114-K. A variant of pMLS114 with a deletion in $s p p \mathrm{R}$ (positions 1983-2540), was obtained by ligating the purified $0.63 \mathrm{~kb}$ $H p a \mathrm{I}-\mathrm{Bg} / \mathrm{II}$ fragment (positions $2540-3169)$ to the $N r u \mathrm{I} / B g / \mathrm{II}-$ digested pMLS114. To introduce a frameshift mutation in spi $A$, the single Bg/II site in pMLS114 was made blunt and the plasmid religated. This resulted in pMLS114-I. A deletion mutation in $s p p T$ was achieved by cutting pMLS114 with SnaBI and EcoRV and religating the resulting $10.8 \mathrm{~kb}$ plasmid to the new construct pMLS114-T. A deletion mutation in $s p p E$ was created by digesting pMLS114 first with $X b o I$; the $X b o I$ ends were made blunt and the linearized plasmid was subsequently cut with $N d e I$. A purified $2 \cdot 1 \mathrm{~kb} N d e I-S_{c a I}$ fragment from pMLS114 was then ligated to the $8.6 \mathrm{~kb} \mathrm{NdeI-Xbol} \mathrm{fragment} \mathrm{resulting} \mathrm{in} \mathrm{a}$ pMLS114 derivative, pMLS114-E, with a deletion of the $3^{\prime}$-end of $s p p E$. The construct pMLS-IP was created using a spi $A$ fragment which was amplified from pMLS114 by PCR (positions 3066-3629); the ermL promoter, derived from the Lactobacillus reuteri erythromycin resistance gene (Axelsson et al., 1988), was cloned on a $0.4 \mathrm{~kb}$ fragment upstream of the spiA gene and the combined fragments were introduced into pLPV111. The ermL promoter is known to be utilized, since this gene is present in pLPV111 conferring erythromycin resistance to $L b$. sake.

Southern and Northern analysis. Chromosomal DNA of $L b$. sake Lb674 was digested with several restriction enzymes. The resulting fragments were separated on a $1 \%(\mathrm{w} / \mathrm{v})$ agarose gel and blotted onto a nylon membrane (Boehringer). Synthetic oligonucleotides used as hybridization probes were labelled with digoxygenin-dUTP from a DIG Oligonucleotide 3 '-End Labeling kit (Boehringer). DNA fragments were labelled by random primed incorporation of digoxygenin-labelled dUTP from a DIG DNA Labeling and Detection kit (Boehringer) and hybridization was performed as recommended by the supplier. No restriction digests were performed in the case of hybridization to $L b$. sake Lb706X and Lb790 DNA. For the plasmidfree strain Lb706X, total DNA was used; for Lb790, the DNA preparation was enriched for either chromosomal DNA (by 'spooling', i.e. winding DNA threads onto the tip of a Pasteur pipette) or plasmid DNA (by a normal plasmid mini-preparation). Total RNA was isolated from $L b$. sake Lb674 and Lb790 according to the procedure described by van der Vossen et al. (1987). The RNA (10 $\mu$ g per lane) was separated on an $1 \%$ agarose gel in the presence of $5.5 \%(\mathrm{v} / \mathrm{v})$ formaldehyde and blotted onto a nylon membrane. Synthetic oligonucleotides and random-labelled DNA fragments were used as hybridization probes. When synthetic oligonucleotides were used, hybridizations were performed at $39^{\circ} \mathrm{C}$ and the last washing step at $52{ }^{\circ} \mathrm{C}$.

DNA sequencing. DNA was sequenced according to the dideoxy chain-termination method of Sanger et al. (1977). The nucleotide sequence of the double-stranded DNA was determined bidirectionally using the Sequenase version 2.0 DNA Sequencing kit (Amersham) in combination with $\left[{ }^{35} \mathrm{~S}\right] \mathrm{dATP} \alpha \mathrm{S}$ $\left(1.5 \times 10^{3} \mathrm{Ci} \mathrm{mmol}{ }^{-1} ; 5.55 \times 10^{13} \mathrm{~Bq} \mathrm{mmol}^{-1}\right.$; DuPont $)$ and appropriate synthetic oligonucleotide primers. PCR fragments amplified from $L$ b. sake Lb706X and Lb790 chromosomes were sequenced using the Sequenase PCR Product Sequencing kit (Amersham). For databank searches, the EMBL and SwissPIR databases were used. Sequence analysis and alignments were performed with the HUSAR program package (release 3.0, EMBL).

\section{RESULTS}

\section{Cloning of the sakacin P gene cluster}

As reported previously, the sakacin $\mathrm{P}$ (sakacin 674) structural gene, $\operatorname{spp} A$, was located on a $3.9 \mathrm{~kb} C l a \mathrm{I}-E c o \mathrm{RI}$ chromosomal DNA fragment of Lb. sake Lb674 (Holck et al., 1994). To find out whether, in addition to $\operatorname{sp} p A$, other ORFs possibly involved in bacteriocin production were present on this fragment, its remaining nucleotide sequence was determined. Computer analysis revealed four additional ORFs which were transcribed in the same direction as $s p p A$ (pBLS1 in Fig. 1). Two of them, $s p p K$ and $s p p \mathrm{R}$, were located upstream, and two, $s p i A$ and $s p p T$, were located downstream of $\operatorname{spp} A$. Database searches revealed that the proteins encoded by these ORFs showed homology to proteins involved in the production of other LAB bacteriocins (see below).

Since the ORFs $s p p K$ and $s p p T$ were not completely contained on the $3.9 \mathrm{~kb} \mathrm{ClaI}-E c o \mathrm{RI}$ insert, Southern hybridization experiments were performed with $L b$. sake Lb674 DNA. For cloning of the remaining part of $s p p K$ a synthetic oligonucleotide FR2 (5'-CTGTTGCACTATT GTTC- $3^{\prime}$ ) complementary to part of the $s p p K$ sequence was used as a probe. The probe identified a $1.3 \mathrm{~kb} \mathrm{HpaII}$ fragment which was ligated into the $\mathrm{Cla}$ I site of $\mathrm{pBlue}$ script $\mathrm{KS}^{+}$, resulting in pBLS2 (Fig. 1). A $3.7 \mathrm{~kb} P v u \mathrm{II}$ fragment hybridizing to the labelled $0.9 \mathrm{~kb} S p e \mathrm{I}-E c o \mathrm{RI}$ fragment of the pBLS1 insert (Fig. 1) was isolated and cloned into the EcoRV site of pBluescript $\mathrm{KS}^{+}$. The resulting plasmid was termed pBLS3 (Fig. 1). Positive E. coli transformants containing the plasmids pBLS2 and pBLS3 were identified by colony hybridization.

\section{DNA sequence analysis}

The DNA sequence of the inserts from pBLS1, pBLS2 and pBLS3 was determined. The combined nucleotide sequence comprises $7597 \mathrm{bp}$ and encompasses the six ORFs $s p p K, s p p R, s p p A$, spiA, $s p p T$ and $s p p E$, the small 


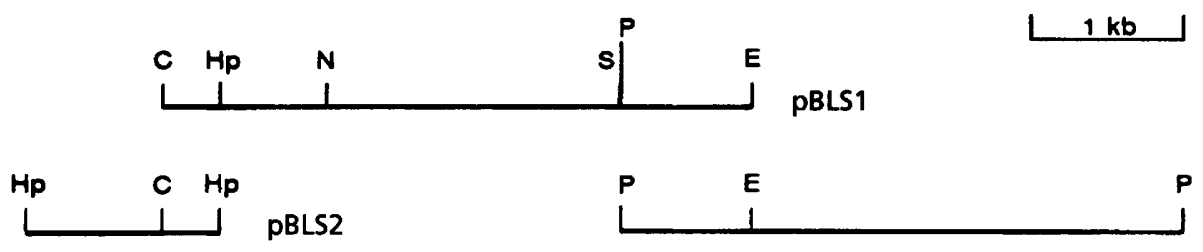

PBLS3

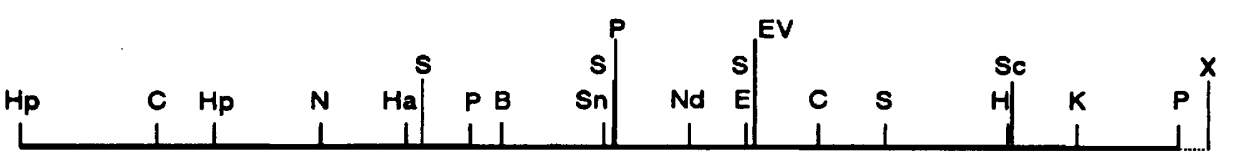

pMLS114

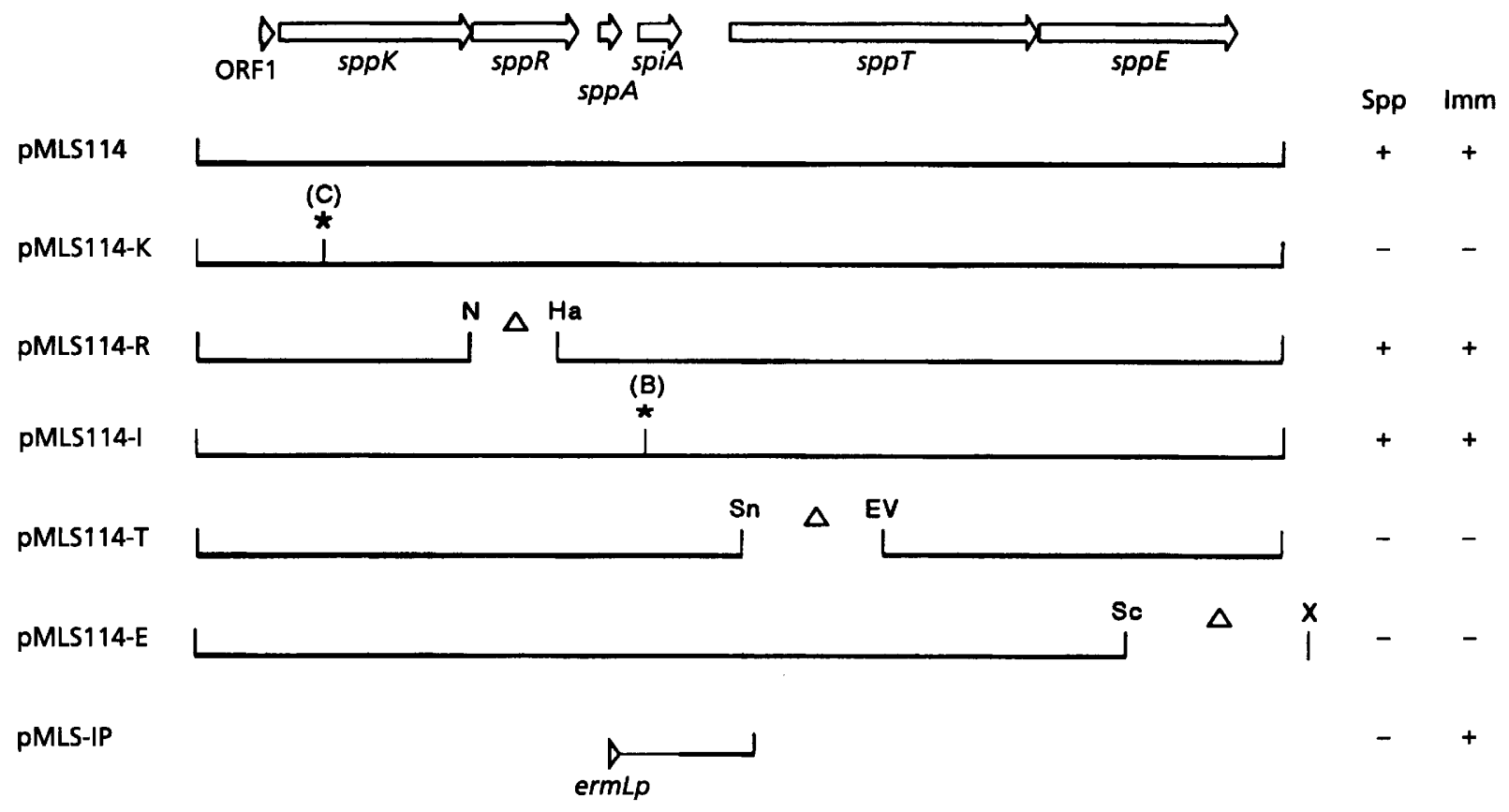

Fig. 1. Schematic overview of the subclones derived from the sakacin P gene cluster. The $7.6 \mathrm{~kb}$ insert in pMLS114 was combined from the inserts of pBLS1, pBLS2 and pBLS3. The location and orientation of the ORFs in pMLS114 are indicated by arrows. Deletion $(\Delta)$ and frameshift mutation $\left(^{*}\right)$ derivatives of pMLS114 are shown below. The arrowhead with the designation ermLp indicates the direction of the ermL promoter present in this construction. The thin line in pMLS-IP represents the ermL promoter sequence (Axelsson et al., 1988). Spp and Imm denote sakacin P production and immunity to sakacin $P$, respectively, of $L b$. sake Lb706X carrying the pMLS114 derivatives. Restriction sites: $B, B g / l l ; C$, Clal; E, EcoRI; EV, EcoRV; H, HindIII; Ha, Hpal; Hp, Hpall; K, Kpnl; N, Nrul; Nd, Ndel; P, Pvull; S, Spel; Sc, Scal; Sn, SnaBI; $X$, Xhol. On the insert of pMLS114 not all of the Hpal and Hpall restriction sites are indicated. The dotted line represents part of the vector's multiple cloning site.

ORF1 upstream of $s p p K$ (Fig. 2), and an incomplete reading frame downstream of $s p p E$ which we refer to as ORF2 (not shown in Fig. 2). Potential ribosome binding sites (RBS) were identified upstream of all ORFs. ORF1 potentially encodes a protein of 36 aa. The $s p p K$ gene encodes a putative protein of 448 aa. Immediately downstream of $s p p K, s p p \mathrm{R}$ starts with the less frequently used leucine initiation codon (TTG) and could encode a protein of 248 aa. Downstream of $s p p R$, a sequence element is located representing a possible rbo-independent transcription termination signal with a calculated $\Delta G$ of $-18.4 \mathrm{kcal}$ $\mathrm{mol}^{-1}\left(-77 \cdot 0 \mathrm{~kJ} \mathrm{~mol}^{-1}\right)$ (Tinoco et al., 1973). The structural gene of sakacin $\mathrm{P}, \operatorname{spp} A$, starts 147 bp downstream of $s p p$ R. It is followed by spi $A$ encoding a potential protein of 98 aa. Downstream of spiA a possible rboindependent transcription terminator with a calculated $\Delta \mathrm{G}$ of $-19.4 \mathrm{kcal} \mathrm{mol}^{-1}\left(-81.2 \mathrm{~kJ} \mathrm{~mol}^{-1}\right)$ was found. The sppT gene starts $350 \mathrm{bp}$ downstream of spiA and could encode a protein of 718 aa. The reading frame $s p p E$ is located immediately downstream of $s p p T$ and predicts a protein of 458 aa. No obvious transcription termination signal was detected in the region downstream of $s p p E$. Potential promotor sequences are located upstream of ORF1, spp $A, s p p T$ and ORF2 (Fig. 2). Thus, three major 
1 CCGGCTCTTTGACCATAAGCACCTAGGTCGATTAATAATTGTTCTTCAGATTTATTGAGA

61 TGAATITTACCAAAGCCAACACTATAAATATAATTTGCGAGGCGGTTGACTAACACTTCA

121 GGATTCTTGGCAGTTTCAAGTGTGAGATAGACCTGACTCAAAACATCGGTAATGTCGAGA

181 AGCGCGTTTGATTTATCTGGATGAGCCATTAGGCTGTTGTAAAGTGTATGAATGTTTTCC

241 TTAGCAATTTCTTGATTAGTCATAATGAAAAGCCTCCACAAAAAGTATTATCAACATCTG

301 TTCTAGTCTTCTTAGTAAATTTTGTCAACTTCAATAGAGTTCTTAACGTTAATCCGAAAA

361 AAACTAACGTTAATATTAAAAAT 2 AGATCCGCTTGTGAATTATGTATAATTTGATTAGA

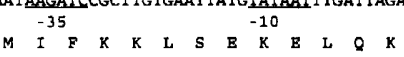

421 CTAAAGAATAGGAGAAAGTATGATGATATTTAAAAAACTTTCAGAAAAAGAATTGCAAAA

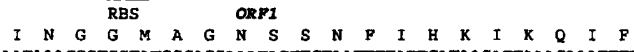

481 AATAAACGGTGGTATGGCAGGAAATAGTTCTAATITIATTCATAAGATTAAACAAATTIT

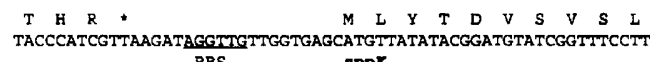

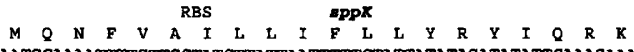

601 AATGCAAAATTTTGTTGCTATCTTATTAATTTTTCTATTATATAGATATATTCAAAGAAA

$\begin{array}{llllllllllllllllllll}I & T & F & K & R & I & I & L & D & I & L & I & A & I & I & F & S & I & L & Y\end{array}$

661 GATAACATTTAAACGGATCATATTAGATATTTTAATAGCGATTATTTTTCAATATTATA

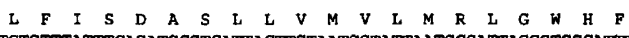

721 TCTGTTTATTTCAGATGCGTCATTACTTGTAATGGTATTAATGCGATTAGGGTGGCATTT

$\begin{array}{llllllllllllllllllll}H & Q & Q & K & E & N & K & I & K & T & T & D & T & A & N & \text { L } & \text { I } & \text { L } & \text { I } & \text { I }\end{array}$

781 TCATCAACAAAAAGAAAATAAGATAAAAACGACTGATACAGCTAATTTAATTCTAATTAT

$\begin{array}{llllllllllllllllllll}V & I & Q & L & L & L & V & A & V & G & T & I & I & S & Q & F & T & I & S & I\end{array}$

841 CGTGATCCAGTTATTGTIAGITGCGGTTGGGACTATTATTAGTCAGTTTACCATATCGAT

$\begin{array}{llllllllllllllllllll}I & K & S & D & F & S & Q & N & I & L & N & N & S & A & T & D & I & T & L & L\end{array}$

901 TATCAAAAGTGATTTCAGCCAAAATATATTGAACAATAGTGCAACAGATATAACTTTATT

$\begin{array}{llllllllllllllllllll}G & I & F & F & A & V & L & F & D & G & \text { L } & F & F & I & L & L & X & N & X & R\end{array}$

961 AGGTATTTTCTTTGCTGTTTTATTTGACGGCTTGTTCTTTATATTATTGAAGAATAAGCG

T E E L

1021 GACTGAATTACAACATTTAAATCAAGAAATCATTGAATTTTCGTTAGAAAAACAATATTT

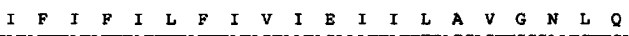

1081 TATATTTATATTTATTTTATTTATAGTAATAGAAatTATTTTAGCAGTTGGAATCTTCA

G $\quad V \quad$ T

1141 AGGAGTAACAGCCACGATATTATTAACCATTATCATTATTTTTTGTGTCCTTATCGGGAT

T F F

1201 GACTITTTGGCAAGTGATGCTTTITTTGAAGGCTTATTCGATTCGCCAAGMAGCAATGA

$\begin{array}{llllllllllllllllllll}Q & L & \text { V } & R & N & Q & Q & L & Q & D & Y & \text { L } & \text { V } & N & \text { I } & E & Q & Q & \text { Y } & \text { T }\end{array}$

E

1321 CGAATTACGGCGATTTAAGCATGATTATCAAAACATCTTATTATCGTTGGAGAGTTTTGC

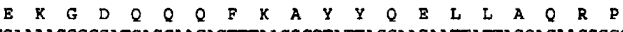

1381 CGAAAAGGCGATCAGCAACAGTTTAAGGCGTATTACCAAGATTATTAGCACAACGGCC

$\begin{array}{llllllllllllllllllll}I & Q & S & B & I & Q & G & A & V & I & A & Q & L & D & Y & L & K & N & D & P\end{array}$

1441 AATTCAAAGTGAAATCCAAGGGGCAGTCATTGCACAACTCGACTACTTGAAAAATGATCC

$\begin{array}{llllllllllllllllllll}I & R & G & \text { L } & V & I & Q & K & F & \text { L } & A & A & K & Q & A & G & V & T & \text { L } & K\end{array}$

1501 TATTCGAGGATTAGTCATTCAAAAGTTITTGGCAGCCAAACAGGCTGGTGTTACTTTAAA

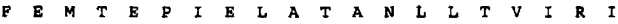

1561 ATTCGAAATGACCGAACCAATCGAATTAGCAACCGCTAATCTATTAACGGTTATTCGGAT

$\begin{array}{llllllllllllllllllll}I & G & I & L & L & D & N & A & I & E & Q & A & V & Q & E & T & D & Q & L & V\end{array}$

1621 TATCGGTATTTTATTAGACAATGCGATTGAACAAGCCGTTCAAGAAACCGATCAATTGGT

$\begin{array}{llllllllllllllllllll}S & C & A & F & L & Q & S & D & G & L & I & E & I & T & I & E & N & T & A & S\end{array}$

1681 GAGTTGTGCTTTCTTACAATCTGATGGTTTAATCGAAATTACGATTGAAAATACGGCCAG

Q V V K K N N L

1741 TCAAGTTAAGAATCTCCAAGCATTITCAGAGTTAGGCTATTCAACGAAAGGCGCTGGTCG

G $T$ T G L

1801 GGGGACTGGTTTAGCTAATGTGCAGGATTTGATTGCCAAACAAACCAATTTATTCTTAGA

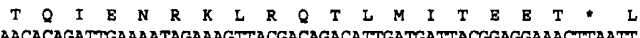

1861 AACACAGATTGAAAATAGAAAGTTACGACAGACATTGATGATTACGGAGGAAACTTAATT

Y $P$ P $Y$ Y L L L E

1921 TGTATCCCGTTTATTTATTAGAGGATGATTTACAGCAACAAGCGATTTATCAGCAAATTA

$\begin{array}{llllllllllllllllllll}A & N & T & I & M & I & N & B & F & A & M & T & L & T & C & A & A & S & D & T\end{array}$

1981 TCGCGAATACGATTATGATTAACGAATTTGCAATGACTTTAACATGCGCTGCCAGTGATA

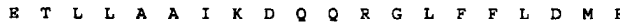

2041 CTGAGACATTGTTGGCGGCAATTAAGGATCAGCAACGAGGTTTATTCTTTTTGGATATGG

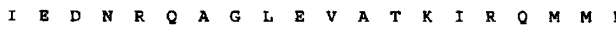

2101 AAATTGAGGATAACCGCCAAGCCGGTTTAGAAGTGGCAACTAAGATTCGGCAGATGATGC

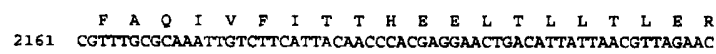

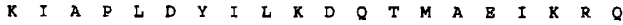
2221 GAAAAATAGCGCCITTAGATTACATTCTCAAGGACCAAACAATGGCTGAAATCAAAAGGC L I I D E D E L L L A 2281 AATTGATTGATGATCTATTGTTAGCTGAGAAGCAAAACGAGGCGGCAGCGTATCACCGAG $\begin{array}{llllllllllllllllllll}N & L & F & S & \mathbf{Y} & \mathbf{X} & \mathbf{I} & \mathbf{G} & \mathbf{P} & \mathbf{R} & \mathbf{F} & \mathbf{F} & \mathbf{S} & \mathbf{L} & \mathbf{P} & \mathbf{L} & \mathbf{X} & \mathbf{E} & \mathbf{V} & \mathbf{V}\end{array}$ $Y$ L Y T E K E N P G H I N L L A V T $R$ 2401 TTTATTTATATACTGAAAAAGAAAATCCGgGTCATATTAATTTGTTAGCCGTTACCAGAA

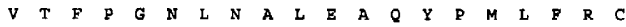
2461 AGGTTACTITTCCAGGAAATTTAAATGCGCTGGAAGCCCAATATCCAATGCTCTITCGGT $\begin{array}{llllllllllllllllllll}D & K & S & Y & L & V & N & L & S & N & I & A & N & Y & D & S & K & T & R & S\end{array}$ 2521 GTGATAAAAGTTACTTAGTTAACCTATCTAATATTGCCAATTATGACAGTAAAACACGGA

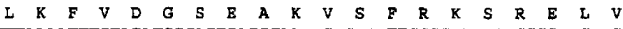
2581 GTTTAAAATTTGTAGATGGCAGTGAGGCAAAAGTCTCGTTCCGGAAATCACGGGAACTAG

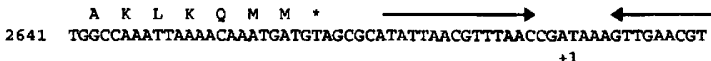

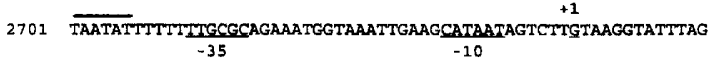
2761 CTGGCTGGCGTAAAGTATGCTTTATAAAATAATATATAGGAGTATGATTCTAATGGAAAA

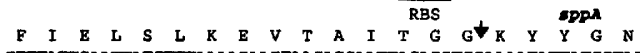
2821 GTTTATTGAATTATCTTIAAAAGAAGTAACAGCAATTACAGGTGGAAAATATTATGGTAA $\begin{array}{cllllllllllllllllllll}G & V & H & C & G & K & H & S & C & T & V & D & W & G & T & A & I & G & N & I\end{array}$ 2881 CGGTGTACACTGTGGAAAACATTCATGTACCGTAGACTGGGGACAGCTATTGGAAATAT

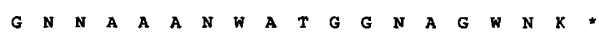
2941 CGgAAATAATGCAGCTGCAAACTGGGCCACAGGCGGAAACGCTGGCTGGAATAAATAATA 3001 AGCAAAACTTAATTTAGATTTAAGGACTCTCTATCATTTGATGGGGATTTTTTAGCTTAT

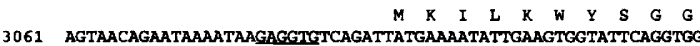

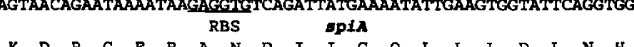

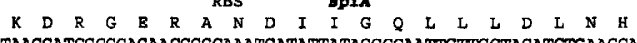
3121 TAAGGATCGCGGAGACGGGCAAATGATATTATAGGCCAATTGTIGCTAGATCTGAACCA $\begin{array}{lllllllllllllllllllll}D & P & K & N & E & \text { H } & \text { L } & \text { E } & \text { A } & \text { I } & \text { L } & \text { I } & \text { N } & Y & Q & \text { N } & \text { E } & \text { I } & K & R\end{array}$ 3181 TGATCCAAAAAATGAACATTTAGAAGCAATATTAATAAATTATCAGAATGAAATTAAAAG $\begin{array}{llllllllllllllllllll}K & E & S & S & V & P & F & I & L & S & R & M & N & I & S & I & A & N & T & I\end{array}$ 3241 GAAAGAAAGTTCGGTGCCATTTATTTTGAGTCGGATGAATATATCAATAGCCAATACAAT $\begin{array}{llllllllllllllllllll}R & R & D & R & L & I & L & T & D & F & Q & B & D & K & L & K & L & L & T & A\end{array}$ 3301 CAGAAGAGATAGGCTCATTTTAACCGATTTTCAGGAGATAAATTGAAATTGTTAACTGC L S N I R Y G Y

3361 GTTGTCTAATATAAGATATGGCTATTAGCAGCTTAATTCTGTAGCACACTATTCTAAGAA 3421 TACGCTAGAACTGTTATATGGAATTITCAATATTAATTTGGTTGATAGTGAACTTGATGA 3481 GATATTCATTATTATAATGTGTCATATAGTACGATTCGTTATTGCTGGTTATGAATACAT

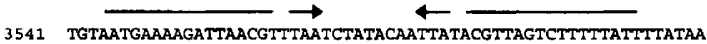

3601 GGAATAGCCATAATATAACAGCTTAGATTTTAAATGCAGCATTAACGTTAATTTTGATAA 3661 ACGTAACGTTAATGGATAATCATCGTETTIACAAATAGTGTATGACATAATTAAGTAATT $-3$ $-10$

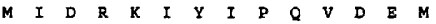

3721 AACTTACGGAGGCTCTTGATGATAGATCGTAAAATTTATATACCACAAGTAGATGAAATC

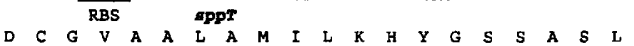

3781 GATTGTGGCGTAGCAGCTTTAGCGATGATTCTTAAACATTATGGTTCTTCAGCTTCGCTG $\begin{array}{llllllllllllllllllll}A & Y & L & R & N & E & A & K & T & D & L & B & G & T & T & A & L & G & L & V\end{array}$

3841 GCTTATTTACGTAATGAGGCTAAAACTGATTTAGAAGGAACAACGGCGCTTGGACTAGTG $\begin{array}{lllllllllllllllllllll}K & T & A & B & N & L & G & F & E & T & X & A & I & Q & A & D & M & S & L & P\end{array}$ 3901 AAGACAGCTGAGAATTTAGGTTTCGAAACGAAGGCGATTCAAGCTGATATGAGTTTGTTT E V V A D D L L 3961 GAAGTCGCAGATTTACCATTTCCTTTTATTGCACATGTTCTAAAAAATGGCGAGCTATTA

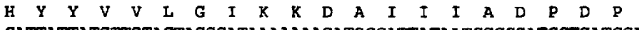
4021 CATTATTATGTTGTACTAGGGATAAAAAAAGATGCCATTATAATCGCCGATCCTGATCCA

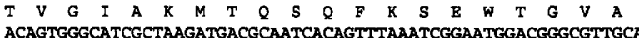

L $F$ I A $P$ X $P$ S $Y$ O $P$ V $K$ Q O $T$ K A S L 4141 TTATTTATTGCTCCAAAACCGAGCTATCAACCAGTTAAGCAGCAAACAAAAGCGAGTTTA

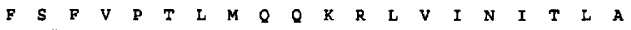
4201 TTTTCATTIGTTCCAACTTTGATGCAGCAAAAGCGATTGGTAATTAATATTACTITGGCG $\begin{array}{lllllllllllllllllllll}A & L & L & I & T & I & I & S & I & L & G & S & Y & F & L & Q & T & V & I & D\end{array}$ 4261 GCGCTACTCATAACCATTATTAGTATTCTAGGATCTTATTTCTTACAGACTGTCATTGAT $T$
ACCTATATCCCAAATAACATGCAGAGCACGCTGGCGATTGTTGCAATTGGTTTAATTATC

Fig. 2. For legend see opposite. 
$\begin{array}{lllllllllllllllllllll} & F & Y & G & F & Q & S & I & F & T & Y & \text { A } & Q & \text { N } & \text { F } & \text { L } & \text { L } & \text { A } & V & \text { L } & G\end{array}$

Q L S I I I L S Y L $R$ V E E L P

4441 CAGCGGTTATCAATTGAGATTATTTTAAGTTACTTAAGACATGTTTTTGAATTACCAATG

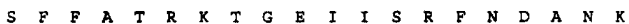

4501 TCTTTTITTGCAACACGTAAAACAGGTGAAATAATTTCACGATTTAATGACGCGAATAAA I I D A 4561 ATTATTGATGCGCTAGCAAGCGCAATTATTTCAATTTTT2TAGATATTACAGTCGTTGT

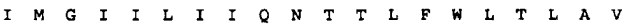
4621 ATTATGGGGATTATTCTGATCATTCAAAATACAACTTTATTCTGGTTAACCTTAGCAGTC

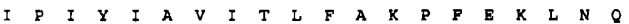
4681 ATTCCAATCTATATTGCCGTGATTACTTTATTTGCAAAACCTTTTGAAAAATTAAATCAA X E 4741 AAGGAAATGGAAAGTAATGCAGTATTGAATTCGGCGATCATTGAAGATTTACATGGCATT $\begin{array}{llllllllllllllllllll}E & T & I & K & A & L & T & S & E & S & E & R & Y & O & K & I & D & T & A & F\end{array}$ 4801 GAAACGATTAAAGCGTTAACTAGTGAAAGTGAACGATATCAAAAAATAGATACAGCATTT

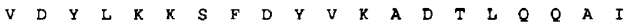
4861 GTTGATTATCTGAAGAAGAGTTTTGACTATGTAAAAGCTGATACATTGCAACAAGCAATT

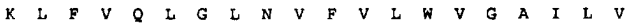
4921 AAGTTGTTTGTCCAATTAGGGCTGAATGTCTTTGTGCTGTGGGTAGGCGCTATTTTAGTC

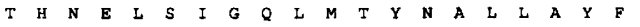
4981 ACGCATAACGAGTTATCAATTGGGCAATTGATGACCTACAATGCCTTGCTGGCGTATTTT $\begin{array}{llllllllllllllllllll}V & N & P & L & Q & N & I & I & N & L & Q & T & K & L & Q & S & A & R & \text { V } & A\end{array}$ 5041 GTAAATCCGTTACAGAATATCATCAATTTACAGACTAAGTTACAGAGCGCGAGGGTAGCC $\begin{array}{llllllllllllllllllll}N & N & R & L & N & E & V & Y & L & V & D & S & \text { B } & F & K & T & E & R & P & I\end{array}$ 4121 AATAATCGGTTGAATGAAGTTTATCTGGTTGATTCTGAGTTCAAGACAGAACGACCAAT

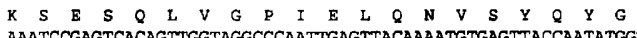
5161 AAATCCGAGTCACAGTTGGTAGGCCCAATTGAGTTACAAAATGTGAGTTACCAATATGGT $\begin{array}{lllllllllllllllllllllll}Y & G & Q & R & V & L & E & S & I & S & L & K & I & E & P & N & B & K & L & T\end{array}$

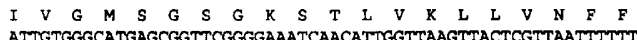
5281 ATTGTGGGCATGAGCGGTTCGGGGAAATCAACATIGGTTAAGTTACTCGTTAATTTTTTT

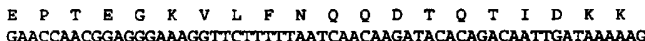
$\begin{array}{llllllllllllllllllll}T & \text { L } & R & Q & \text { F } & \text { V } & \text { N } & \text { Y } & \text { I } & \text { A } & \text { Q } & \text { T } & \text { P } & \text { Y } & \text { I } & \text { F } & \text { S } & \text { G } & \text { S } & \text { I }\end{array}$ 5401 ACATTGCGGCAGTTTGTTAACTATATTGCACAGACACCGTACATTTTCTCAGGAAGTATT

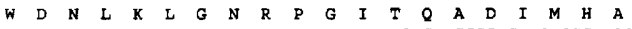
5461 TGGGATAATCTTAAGTTAGGTAATCGGCCAGGAATCACACAAGCGGACATCATGCATGCO $\begin{array}{lllllllllllllllllllll}C & E & L & A & E & I & K & N & D & I & E & K & M & P & L & Q & F & E & T & L\end{array}$ 5521 TGTGAGCTAGCAGAGATAAAGAATGATATTGAAAAAATGCCGCTCCAATTTGAAACATTA L $D$ D E 5581 TTGGATGAAGATGGAAACACATTGTCAGGTGGTCAAAAACAGCGATTAACAATTGCGCGA

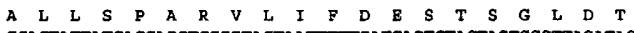
5641 GCACTATTATCACCAGCTCGGGTACTAATTTTIGATGAGTCTACTAGTGGGTTAGATACG I $T$ T $E$ E G 5701 ATAACAGAGGGGCTATTAGTTGATCATCTAATGGCGTTAGAAGAAAGAACAATCATTTTC $\begin{array}{llllllllllllllllllll}I & A & H & R & \text { L } & A & I & A & K & K & T & N & N & I & \text { L } & V & \text { L } & \text { E } & N & G\end{array}$ 5761 ATAGCGCATCGTTTAGCGATTGCTAAGAAAACGAACAATATTCTTGTTTPAGAAAATGGT $\begin{array}{llllllllllllllllllll}S & V & V & E & T & G & T & H & D & A & L & V & D & T & Q & G & R & Y & Y & Q\end{array}$ 5821 AGTGTTGTIGAAACTGGGACACATGATGCGTIGGTGGATACACAAGGGCGATATTACCAA L L N H * M D K E F L E 5881 TTGCTCAATCATTAGTGGGGGATTAAAGTATGGATAAAGAGTTTCTGGAGAGCAGTGAG $Y$ S R R R AppE

$5941 \underset{\text { TTTATAGTGCGCGGTTTAAAAATTTTTCAACACTATTAATTATGCCAATTGCAGTTCTAC }}{\text { Y }}$

C L V V C I $F$ S $F$ F G K 6001 TTTGTCTCGTATGCATCTIITCTITTITTGGTAAACGAGAAATTACGATTGAAGGTCAAC $\begin{array}{llllllllllllllllllll}D & L & T & T & N & K & Q & I & P & I & L & Q & A & S & T & N & S & V & L & K\end{array}$ 6061 GTGATTTAACGACGAATAAACAGATTCCAATATTACAAGCCTCTACTAATAGTGTATTAA $\begin{array}{llllllllllllllllllll}Q & N & Y & \text { L } & \text { K } & \text { E } & G & \text { K } & \text { F } & \text { V } & \text { K } & \text { K } & G & \text { Q } & \text { T } & \text { L } & \text { L } & \text { V } & \text { Y } & \text { O }\end{array}$

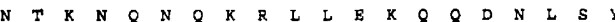
6181 AAAATACTAAAAATCAGAATCAGAAACGGCTATTAGAAAAACAACAGGATAATCTGAGT

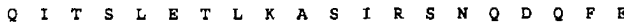
6241 ATCAGATTACGAGTTTGGAAACATTGAAAGCTAGCATTCGCAGTAATCAAGACCAATTTG

$\begin{array}{llllllllllllllllllll}N & N & D & Q & F & G & Y & R & D & L & L & R & G & Y & L & D & Q & R & Q & V\end{array}$ 6301 AGAATAATGATCAGTTTGGTTACAGAGATTTATTACGAGGTTATCTTGACCAAAGACAAG

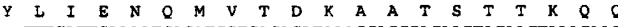
6361 TTTATTTGATTGAAAATCAGATGGTGACAGATAAAGCAGCGACAAGTACAACTAAACAAC

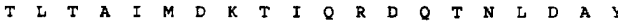
6421 AGACATIGACAGCGATTATGGATAAGACAATTCAACGAGATCAAACAAATCTTGACGCGT

$\begin{array}{lllllllllllllllllllllllllll}Q & A & L & Y & Q & S & I & K & T & N & K & V & Y & S & S & T & G & K & Y & N\end{array}$
$\begin{array}{lllllllllllllllllll}Y & L & Y & E & N & Y & Q & T & X & V & X & A & M & S & D & X & N & E & Q\end{array}$ 6541 ATTATCTTTACGAGAACTATCAAACGAAAGTAAAAGCGATGTCTGATAAAAATGAACAAA

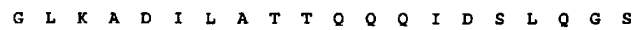
6601 GTGGTPTAAAAGCAGATATTTTAGCAACGACGCAACAACAAATTGATAGTTTACAAGGTA

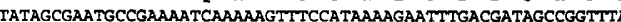

$\begin{array}{llllllllllllllllllll}T & N & T & N & N & E & K & L & A & L & L & E & A & 0 & O & T & O & S & A & N\end{array}$

6721 ATACGAATACTAATAATGAAAAGTTAGCATTATTAGAAGCACAGCAAACACAATCAGCAA

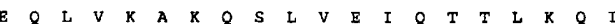

6781 ATGAACAGCTTGTAAAAGCTAAACAATCACTTGTCGAAATACAAACAACTTTAAAAACAAA

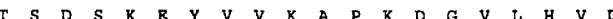

6841 TAACGAGTGATTCTAAGGAATACGTGGTTAAAGCACCTAAAGACGGAGTTCTACATGTTG

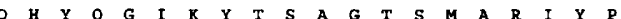

6901 ATGATCACTATCAAGGGATTAAGTATACGAGTGCTGGTACCAGTATGGCGCGGATTTATC

$\begin{array}{llllllllllllllllllll}V & L & A & D & O & K & R & L & K & I & E & A & L & I & P & V & D & D & I & S\end{array}$

6961 CGGTATTAGCTGATCAGAAGAGATTAAAAATAGAAGCGCTTATTCCAGTTGATGATATTT

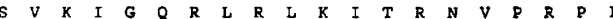

2021 CATCAGTTAAAATTGCACAMGACTACGTTTGAMAATTACGCGOMATGTCCAAGRCCAA

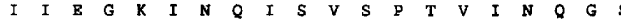

7081 TTATTAT

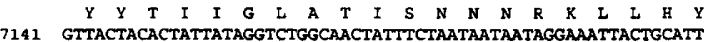

$\begin{array}{llllllllllllllllllll}G & M & T & G & K & I & A & I & I & T & G & K & T & T & F & F & N & Y & Y & K\end{array}$

7201 ATGGAATGACCGGTAAAATAGCAATTATCACTGGTAAGACAACATTCTTCAACTATTACA

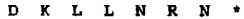

7261 AAGATAAGTTGTTGAATAGAAATTAGGTGGTATTACCATATAAATTATGAGAGTTTCCT

7321 TGGTTTAAAATTAATTGAAAATTGATATTAGCGTTTAACAGTTAAATTAATACGTTAAT

7381 AATTTTTTTGTCTITAAATAGGGATTTGAAGCATAATGGTGTTATAGCGTACTTAGCTGC

7441 CCAGCATATATGTATTCTATAAAATACTATTACAAGGAGATTTTAGATATGCAAAATAC

7501 AAAGAACTAAGCGTAGTAGAATTACAACAAATTCTTGGAGGAAAACGTGCTAGCTTTGGT

7561 AAATGTGTAGTTGGTGCTTGGGGAGCTGGTGCAGCTG 7597

Fig. 2. Nucleotide sequence of the sakacin $P$ gene cluster and the predicted amino acid sequences of the ORFs ORF1, sppK, sppR, sppA, spiA, sppT and sppE. Putative -35 and -10 promotor regions and possible ribosome-binding sites (RBS) are underlined. The divergent arrows above the DNA sequence indicate putative transcription terminators. Translation termination codons are marked by asterisks. The transcription start of the sppA gene determined by Tichaczek et al. (1994) is underlined and marked with $(+1)$. The vertical arrow marks the processing site of SppA. The parts of this sequence previously published by Holck et al. (1994) and Tichaczek et al. (1994) comprise positions 2792-3131 and 2384-3737, respectively.

transcripts are predicted from the sequence, the first encompassing ORF $1 / s p p K / s p p R$, the second $s p p A / s p i A$, and the third, at least $s p p T$ and $s p p E$.

\section{Homologies of the $\operatorname{spp} K$ and $\operatorname{sppR}$ gene products}

The putative proteins encoded by $s p p K$ and $s p p \mathrm{R}$ are homologous to several proteins of two-component signal transducing systems (Parkinson \& Kofoid, 1992; Stock et al., 1989). These systems in general consist of a histidine protein kinase (HPK) and a response regulator protein (RR). SppK shows strongest similarity to $\mathrm{P} \operatorname{lnB}(59 \%)$, the suggested HPK of the plantaricin A operon from $L b$. plantarum C11 (Diep et al., 1994). SppR shows strong similarity to $\mathrm{P} \ln \mathrm{D}(68 \%)$ and $\mathrm{P} \operatorname{lnC}(65 \%)$, the proposed RR proteins of the plantaricin A operon. SppK and SppR are also homologous to the proposed two-component regulatory system of the sakacin A gene cluster, SapK (54\% similarity) and SapR (50\% similarity) (Axelsson \& Holck, 1995). SppK/SppR also revealed similarity to the 
AgrB/AgrA system from Stapbylococcus aureus which is involved in the post-exponential expression of proteins (AgrB 54\%, AgrA 50\%) (Kornblum et al., 1990; Peng et al., 1988). SppK and SppR displayed all the general features of HPKs and RRs as described by Stock $e t$ al. (1989), such as conserved amino acid residues, transmembrane regions, etc. (not shown).

\section{Homologies of the sppA and spiA gene products}

Homology of sakacin P to other class II bacteriocins has been discussed elsewhere (Holck et al., 1994; Tichaczek $e t$ al., 1994). The reading frame spi $A$ is identical to the proposed ORFY protein from the sakacin P site of $L b$. sake LTH673, a strain which was isolated and investigated by Tichaczek et al. (1994). The DNA sequence of the sakacin P site published by Tichaczek et al. (1994) comprises positions 2384-3737 of our sequence. Except for an additional $T$ residue in position 2426 and a missing $\mathrm{T}$ residue in position 2471 it is identical to the sequence shown in Fig. 2. In addition, the putative spi $A$ product shows $61 \%$ similarity to the predicted protein encoded by ORF- $\beta 3$ of the carnobacteriocin B2 site from C. piscicola LV17B (Quadri et al., 1994).

\section{Homologies of the sppT and SppE gene products}

The deduced SppT protein is homologous to proteins of the HlyB family of ATP-dependent translocators, which are involved in the signal-sequence independent transport of proteins across the bacterial membrane. Homologies exist to SapT of $L b$. sake Lb706 (79\% identity), to ComA of Streptococcus pneumoniae (75\%), to LcaC of Leuconostoc gelidum UAL187 (58\%), to MesD of Leuconostoc mesenteroides Y105 (58\%), to $\mathrm{LcnC}$ of Lc. lactis subsp. lactis biovar. diacetylactis WM4 (55\%), and to PedD (54\%) of $P$. acidilactici PAC-1.0 (Axelsson \& Holck, 1995; Fremaux et al., 1995; Hui \& Morrison, 1991; Marugg et al., 1992; Stoddard et al., 1992; van Belkum \& Stiles, 1995). These proteins are the predicted translocators of sakacin $A$, leucocin A, mesentericin Y105, lactococcin A and pediocin PA-1, respectively. In $S$. pneumoniae, ComA was proposed to be responsible for the secretion of a competence factor which coordinates the induction of genetic competence among the cells. Significant homology of SppT was also observed to HlyB ( $27 \%$ identity), a protein which is essential for haemolysin A secretion in E. coli (Felmlee et al., 1985). With regard to other members of this family of transporters, SppT was predicted to contain several membrane-spanning domains within the $\mathrm{N}$-terminal half and about 200 conserved aa residues within the C-terminal part (not shown). The former was also homologous to the suggested proteolytic domain of bacteriocin ABC (ATP-binding cassette) exporters responsible for cleavage of the bacteriocin leader peptide (Håvarstein et al., 1995). The latter contained the conserved ATP-binding site, invariably found in the superfamily of ABC exporters (Fath \& Kolter, 1993).

The $s p p E$ product is homologous to SapE of the sakacin A gene cluster ( $57 \%$ identity), to LcaD of the leucocin A site $(33 \%)$, to MesE of the mesentericin Y105 locus $(32 \%)$, to $\operatorname{ComB}(30 \%)$, to $\operatorname{LcnD}(29 \%)$, and to HlyD $(25 \%)$. These proteins are viewed as accessory proteins for the ABC transporters (Axelsson \& Holck, 1995; Blight \& Holland, 1990; Fath \& Kolter, 1993; Felmlee $e t$ al., 1985; Fremaux et al., 1995; Hui et al., 1995; Mackman et al., 1986; van Belkum \& Stiles, 1995). A commom feature of SppE and other HlyD analogues is that they are largely hydrophilic except for an approximately 20 aa hydrophobic region close to the $\mathrm{N}$-terminus (not shown).

\section{Northern analysis}

Total RNA of $L b$. sake Lb674 was hybridized to probes specific for the predicted transcription units. RNA of strain Lb790 was used as a negative control. A $2.3 \mathrm{~kb}$ signal was detected with a DNA fragment specific for $s p p K$ and $s p p R$ (Fig. 3b). This mRNA size corresponds well to the expected ORF1 $/ s p p K / s p p R$ transcript. A synthetic oligonucleotide M3R12 (5'-TCCACCTGTAATTGCTG-3') specific for $\operatorname{sp} p A$ detected two mRNA signals of $0.9 \mathrm{~kb}$ and $0.4 \mathrm{~kb}$ (Fig. 3a). This suggests that $s p p A$ is transcribed both in a transcription unit with spi $A$ and in a mRNA encompassing only the $s p p A$. cistron. However, no obvious transcriptional termination structure was found in the corresponding DNA region downstream of $s p p A$. Similar results were obtained by Tichaczek et al. (1994) using mRNA from their strain $L b$. sake LTH673. The weaker hybridization signals also present in the control lanes corresponded to the $23 \mathrm{~S}$ and 16S rRNAs (Fig. 3). When random-labelled pBLS3 specific for $s p p T / s p p E$ was used as a probe, a faint signal was detected at $6.9 \mathrm{~kb}$ (not shown). It is at present uncertain whether this represents a read-through transcript starting from the promoter in front of ORF1 or a transcript starting in front of $s p p T$ and extending beyond $s p p E$ and ORF2. Difficulties in detecting transcripts involved in bacteriocin systems have been encountered previously (Axelsson \& Holck, 1995).

\section{Deletions/mutations in the spp gene cluster and expression in sakacin-negative $\boldsymbol{L} \boldsymbol{b}$. sake strains}

The inserts of pBLS1, pBLS2 and pBLS3 were cloned as a continuous sequence of $7.6 \mathrm{~kb}$ into the vector pLPV111, resulting in pMLS114 (Fig. 1). The sakacin-P-sensitive $\left(\mathrm{Imm}^{-}\right)$and bacteriocin-deficient $\left(\mathrm{Bac}^{-}\right)$hosts $L b$. sake Lb790 and Lb706X transformed with pMLS114 corresponded to the parental strain Lb674 with respect to the extent of bacteriocin production and immunity. Thus, pMLS114 contained all information necessary to confer the ability of sakacin $\mathrm{P}$ production and immunity. To establish whether $s p p K, s p p \mathrm{R}, s p i A, s p p T$ and $s p p E$ are essential for bacteriocin production, frameshift or deletion mutations were introduced in the respective genes on pMLS114. Sakacin P production and immunity were tested in Lb. sake Lb706X (Fig. 1) and Lb790 (not shown in Fig. 1) after transformation with the pMLS114 derivatives. Transformants carrying the derivative with a frameshift in $s p p K$ (pMLS114-K) and a deletion in $s p p T$ (pMLS114-T), respectively, did not produce bacteriocin 

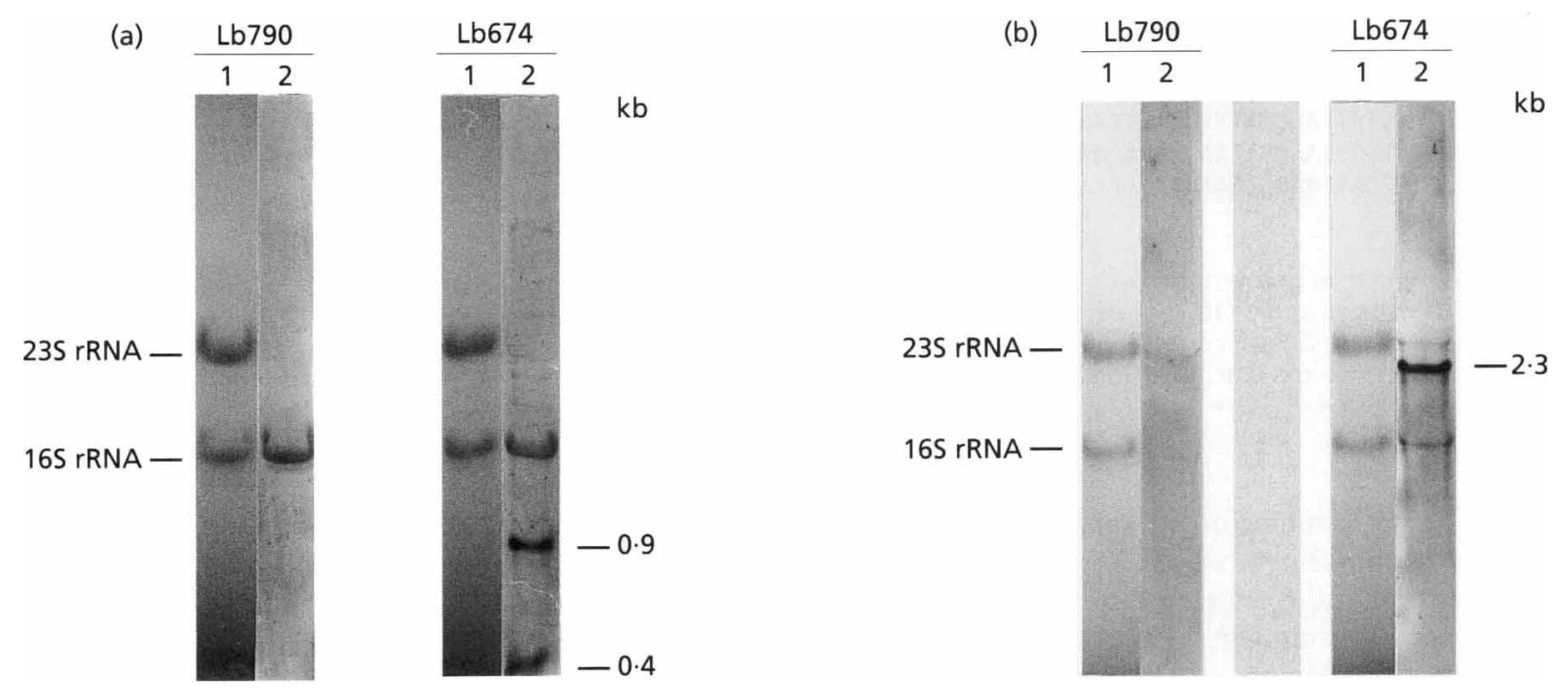

Fig. 3. Northern blot analysis of total RNA from $L$ b. sake $L b 674\left(\mathrm{Bac}^{+}\right)$and from $L b$. sake $L b 790\left(\mathrm{Bac}^{-}\right)$. Before blotting the RNA onto a nylon filter the $23 S$ and 165 rRNA was visualized by UV-shadowing. Lanes: 1, UV-shadowing photograph of the agarose gel showing the $16 \mathrm{~S}$ and 235 rRNA used as size markers (Brosius et al., 1968, 1980); 2, hybridization of RNA (a) to the sppA-specific oligonucleotide probe M3R12 and (b) to a randomly labelled $1.8 \mathrm{~kb}$ Clal-Spel DNA fragment specific for sppK and sppR.

and were sensitive to sakacin $\mathrm{P}$, indicating that $s p p K$ and $s p p T$ were necessary. A deletion mutation in $s p p E$ (pMLS114-E) resulted in Lb706X transformants exhibiting a Spp ${ }^{-}, \mathrm{Imm}^{-}$phenotype. However, the Lb790 transformants carrying pMLS114-E were able to produce bacteriocin and also were immune to sakacin P. Somewhat surprisingly, the mutations in $s p p R$ (pMLS114-R) and spiA (pMLS114-I) had no effect; the transformants were in these cases not distinguishable from $L b$. sake Lb706X carrying pMLS114. However, cells of Lb706X transformed with pMLS-IP were immune to sakacin P, showing the involvement of spiA in immunity.

\section{Presence of sppR and spiA analogues in Lb. sake Lb706X and Lb790 chromosomes}

The results obtained with the derivatives pMLS114-R and pMLS114-I prompted us to investigate if the strains $L b$. sake Lb706X and Lb790 contained genes that could complement these mutations. This was first done with hybridization and gene-specific probes. A $s p p R$-specific probe was made by PCR using pMLS114 as a template. The primers were chosen to amplify a fragment corresponding to position 1940-2615 in the reported sequence (Fig. 2). In an analogous manner, a PCR fragment corresponding to position $3072-3623$ was used as a spiAspecific probe. Hybridization to DNA from $L b$. sake Lb706X and Lb790 with both probes resulted in strong signals from the chromosomal band from both strains (not shown). Next, the same primers used to make the $s p p \mathrm{R}$ - and spiA-specific probes were used in PCR reactions with Lb706X and Lb790 chromosomal DNA as templates. With both $s p p R$ and $s p i A$ specific primers, PCR fragments were obtained that were of the same size as when using pMLS114 as a template. Sequencing of these fragments, corresponding to $70-80 \%$ of the genes, revealed that Lb706X and Lb790 have chromosomal analogues of $s p p \mathrm{R}$ which were $100 \%$ identical between each other at the amino acid level and $97 \%$ identical to $s p p \mathrm{R}$ at the DNA level. The spiA analogues on the chromosome of Lb706X and Lb790 were $100 \%$ identical to spiA at the DNA level.

\section{DISCUSSION}

The sakacin $\mathrm{P}$ gene cluster from Lb. sake Lb674 was cloned, sequenced and expressed in the bacteriocinnegative hosts $L b$. sake Lb790 and Lb706X. By mutation analyses it was shown that $s p p K, s p p T$ and $s p p E$ were essential for sakacin $\mathrm{P}$ production and immunity in Lb706X. We also showed that spiA under the control of a promoter that functions in $\mathrm{LAB}$ conferred immunity. These results, together with the homologies of SppK/ SppR and SppT/SppE to the proteins of bacterial twocomponent regulatory systems and signal-sequence-independent transport systems, respectively, indicate that sakacin $\mathrm{P}$ production in $L b$. sake Lb674 is controlled by a two-component regulatory system and that its secretion is dependent on a dedicated transport system.

In typical bacterial two-component regulatory systems, a transmembrane HPK is responsible for reception and transduction of an environmental signal to a cytoplasmic RR protein, which mediates a response within the cell. Homology comparisons revealed that $\mathrm{SppK} / \mathrm{SppR}$ belong to the AgrB/AgrA subfamily of the HPK/RR systems. The agr (accessory gene regulator) locus regulates the expression of several virulence determinants and other exoproteins during post-exponential growth (Kornblum et al., 1990; Peng et al., 1988). AgrA functions as a transcriptional regulator (Parkinson \& Kofoid, 1992; 
sppA (2669)

ORF2 (7345)

ORF1 (339)

$\operatorname{sppT}(3638)$

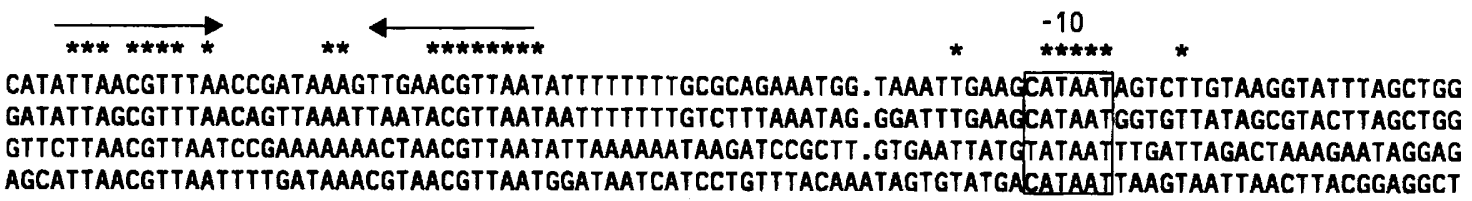

Fig. 4. Sequence alignment of promoter regions within the spp gene cluster. Identical nucleotides are indicated by asterisks, the suggested -10 region is boxed and inverted repeats are indicated by arrows. ORF 2 is the reading frame downstream of sppE not completely contained on the $7.6 \mathrm{~kb}$ insert of pMLS114 (not shown in Fig. 2). Numbers in parentheses denote the start positions of the respective sequences in Fig. 2

Stock et al., 1989). A mutation in $s p p K$ abolished both production and immunity, while immunity could be obtained by placing spiA under the control of a constitutive, heterologous promotor. These results suggest that the Spp signal transducing system acts at the transcriptional level, similar to AgrB/AgrA. Since sakacin P is produced constitutively by $L b$. sake Lb674 in MRS medium (data not shown), nothing is known about the nature of the signal that triggers its production.

Both HPK and RR proteins are also essential for the biosynthesis of several other bacteriocins as shown by mutational analyses of the respective genes in bacteriocinproducing strains (Axelsson \& Holck, 1995; Klein et al., 1993; van der Meer et al., 1993). Although the necessity of SppR for sakacin P production could not be shown in the Lb. sake Lb706X and Lb790 genetic background, SppR is probably essential for sakacin $\mathrm{P}$ production in other hosts and in the donor strain Lb. sake Lb674. The explanation for the apparent non-necessity of $s p p R$ in Lb706X probably lies in the fact that a chromosomal analogue is present in this strain (and in Lb790). Assuming a classical route for signal transduction involving a HPK and a RR, the chromosomally encoded RR is only activated in the presence of an intact SppK. Otherwise it would also be able to complement the $s p p K$ mutation. It is worthy of note that such complementation was not seen in the sakacin A system using the same host strain (Axelsson \& Holck, 1995), indicating that the sakacin A and P systems cannot complement each other, despite a high level of amino acid sequence similarity in the HPK and RR proteins.

The Imm ${ }^{+}$phenotype of pMLS-IP transformants strongly suggests that spi $A$ is the immunity gene in the sakacin $\mathrm{P}$ system. This result and results obtained with pMLS114-I (mutated spiA) at first appear to be contradictory. However, using the same approach as described above for the RR, it was found that a copy of spi $A$ is present in the chromosome of both $L b$. sake Lb706X and Lb790. This gene is normally not expressed in these strains since they are $\mathrm{Imm}^{-}$. However, assuming a transcriptional activation event involving SppK/SppR, it may be expressed when the $s p p$ gene cluster is introduced, thus complementing the mutation in spiA. Our results therefore indicate the presence of an incomplete sakacin $\mathrm{P}$ system (at least $s p p \mathrm{R}$ and spi $A$ analogues) on the chromosome of two separate $L b$. sake strains. We do not know the relative organization of the $s p p R$ and $s p i A$ analogues on the chromosomes of
Lb706X and Lb790 since no restriction enzyme mapping was done. The significance of these findings needs to be studied further. It can also be deduced that the gene products from $s p p T$ and $s p p E$ are necessary not only for production (obvious from the homology with known processing and transport systems, see below), but also for immunity in the normal case (Fig. 1). However, similar to the situation described above for SppK, the involvement of SppT and SppE in immunity must be on the transcription level since spiA under control of a heterologous promotor confers immunity.

Spp $\mathrm{T}$ belongs to the HlyB family of signal-sequenceindependent translocator proteins (Blight \& Holland, 1990; Mackman et al., 1986). This family also includes SapT, LcaC, LcnC and PedD, which are essential for the production of sakacin $A$, leucocin $A$, lactococcin $A$ and pediocin PA-1, respectively. All proteins exported by the HlyB-like transporters lack a classical signal sequence which is required for export in the general secretory pathway. ComA, which is most similar to SppT, is also a member of this protein family. However, in $S$. pneumoniae ComA is not involved in bacteriocin export but is assumed to be responsible for the secretion of the competence factor (Chandler \& Morrison, 1987).

SppE is a HlyD-like protein which is required for sakacin $\mathrm{P}$ production and immunity in $\mathrm{Lb}$. sake Lb706X but not in Lb. sake Lb790. In E. coli, HlyD is necessary for the translocation of haemolysin A. In the haemolysin translocation model, HlyD together with HlyB forms a specific secretory complex which is responsible for the recognition and export of haemolysin across the cytoplasmic membrane. Because of the homology between SppE and HlyD we assume that SppT/SppE form the secretory unit for sakacin $\mathrm{P}$ export. Requirement of HlyD analogues for bacteriocin production was established for several other bacteriocin systems (Axelsson \& Holck, 1995; Marugg et al., 1992; Stoddard et al., 1992; van Belkum \& Stiles, 1995). In the haemolysin model, HlyD spans the periplasm and is anchored in the inner membrane by its hydrophobic $\mathrm{N}$-terminal region. It is assumed to connect the E. coli inner and outer membranes and facilitate the export of haemolysin through both membranes. Because secreted proteins in Gram-positive bacteria have only one membrane to traverse, the role of $\mathrm{SppE}$ in our system is not clear (Fath \& Kolter, 1993). Why $s p p E$ was not essential in $L b$. sake $\mathrm{Lb} 790$ is unknown. A labelled $s p p E$-specific PCR fragment derived from pMLS114 could not detect a 
homologous gene in Lb790. This could mean that Lb790 in contrast to $L b$. sake Lb706X is able to supply an accessory protein from another transport system to complement the destroyed $s p p E$ gene.

Certain sequence similarities upstream of the suggested promoter regions were noted in front of ORF1, $s p p A$, $s p p T$ and ORF2 (Fig. 4). These may be of significance in transcriptional control of the system. Such regions were also found in the sakacin A system and shown to be necessary for proper expression of the sap genes (Axelsson \& Holck, 1995). The $18 \mathrm{~N}$-terminal residues of the putative peptides encoded by ORF1 and ORF2 exhibit significant similarities with leader sequences of class II bacteriocins, including a potential double-glycine cleavage site. These features, together with the DNA sequence homologies upstream of the promoter regions, may indicate that ORF1 and ORF2 have a function in the sakacin P system. The putative mature ORF1 peptide was not homologous to any known peptide in the databases searched but a function in the sakacin P system cannot be excluded since the gene was not inactivated in this study.

In conclusion, the gene cluster involved in sakacin $\mathrm{P}$ production and immunity shows a high degree of similarity to other bacteriocin gene clusters from lactic acid bacteria. In particular, it is similar to the sakacin A gene cluster, although the organization of the genes is somewhat different (Axelsson \& Holck, 1995). Both encode a putative two-component signal transducing system, which seems to act at the transcriptional level in the expression of the genes encoding actual functional proteins, i.e. structural, immunity and transport genes. However, further studies are necessary to determine the precise mechanisms of regulation. The identification of the signal that induces the HPK/RR system should provide a key for a better understanding of this regulation. Our finding that analogues of some of the genes in the $s p p$ cluster can be found on the chromosome of other, bacteriocin-negative $L b$. sake strains is interesting and raises questions regarding the origin and evolution of these systems.

\section{ACKNOWLEDGEMENTS}

This study was supported by the Bavarian State Ministry of Economy and Transport, project number 0703/68560/38/92. We want to thank Dr. Bernd Rautenstrau $\beta$ for his help in computer analysis of the sequence data, and Beate Beier, Merete Bjørnslett and Birgitta Baardsen for excellent technical assistance.

\section{REFERENCES}

Aukrust, T. \& Blom, H. (1992). Transformation of Lactobacillus strains used in meat and vegetable fermentations. Food Res Int 25, 253-261.

Axelsson, L. \& Holck, A. (1995). The genes involved in production of and immunity to sakacin A, a bacteriocin from Lactobacillus sake Lb706. J Bacteriol 177, 2125-2137.

Axelsson, L. T., Ahrné, S. E. I., Andersson, M. C. \& Ståhl, S. R. (1988). Identification and cloning of a plasmid-encoded erythro- mycin resistance determinant from Lactobacillus reuteri. Plasmid 20, $171-174$.

Axelsson, L., Holck, A., Birkeland, S. E., Aukrust, T. \& Blom, H. (1993). Cloning and nucleotide sequence of a gene from Lactobacillus sake Lb706 necessary for sakacin A production and immunity. Appl Environ Microbiol 59, 2868-2875.

van Belkum, M. J. \& Stiles, M. E. (1995). Molecular characterization of genes involved in the production of the bacteriocin leucocin $\mathrm{A}$ from Leuconostoc gelidum. Appl Environ Microbiol 61, 3573-3579.

van Belkum, M. J., Hayema, B. J., Jeeninga, R. E., Kok, J. \& Venema, G. (1991). Organization and nucleotide sequences of two lactococcal bacteriocin operons. Appl Environ Microbiol 57, 492-498.

Blight, M. A. \& Holland, I. B. (1990). Structure and function of haemolysin B, P-glycoprotein and other members of a novel family of membrane translocators. Mol Microbiol 4, 873-880.

Brosius, J., Palmer, M. L., Kennedy, P. J. \& Noller, H. F. (1968). Complete nucleotide sequence of a 16S RNA gene from Escherichia coli. Proc Natl Acad Sci US A 75, 4801-4805.

Brosius, J., Dull, T. J. \& Noller, H. F. (1980). Complete nucleotide sequence of a $23 \mathrm{~S}$ ribosomal RNA gene from Escherichia coli. Proc Natl Acad Sci US A 77, 201-204.

Chandler, M. S. \& Morrison, D. A. (1987). Competence for genetic transformation in Streptococcus pneumoniae: molecular cloning of com, a competence control locus. J Bacteriol 169, 2005-2011.

Diep, D. B., Håvarstein, L. S., Nissen-Meyer, J. \& Nes, I. F. (1994). The gene encoding plantaricin A, a bacteriocin from Lactobacillus plantarum $\mathrm{C} 11$, is located on the same transcription unit as an agrlike regulatory system. Appl Environ Microbiol 60, 160-166.

Fath, M. J. \& Kolter, R. (1993). ABC transporters: bacterial exporters. Microbiol Rev 57, 995-1071.

Felmlee, T., Pellett, S. \& Welch, R. A. (1985). Nucleotide sequence of an Escherichia coli chromosomal hemolysin. J Bacteriol 163, 94-105.

Fremaux, C., Héchard, Y. \& Cenatiempo, Y. (1995). Mesentericin Y105 gene clusters in Leuconostoc mesenteroides Y105. Microbiology 141, 1637-1645.

Hastings, J. W., Sailer, M., Johnson, K., Roy, K. L., Vederas, J. C. \& Stiles, M. E. (1991). Characterization of leucocin A-UAL 187 and cloning of the bacteriocin gene from Leuconostoc gelidum. J Bacteriol 173, 7491-7500.

Håvarstein, L. S., Diep, D. B. \& Nes, I. F. (1995). A family of ABC transporters carry out proteolytic processing of their substrates concomitant with export. Mol Microbiol 16, 229-240.

Henderson, J. T., Chopko, A. L. \& van Wassenaar, P. D. (1992). Purification and primary structure of pediocin PA-1 produced by Pediococcus acidilactici PAC-1·0. Arch Biocbem Biophys 295, 5-12.

Hillier, A. J. \& Davidson, B. E. (1991). Bacteriocins as food preservatives. Food Res Quart 51, 60-64.

Holck, A., Axelsson, L., Birkeland, S.-E., Aukrust, T. \& Blom, H. (1992). Purification and amino acid sequence of sakacin $A$, a bacteriocin from Lactobacillus sake Lb706. J Gen Microbiol 138, 2715-2720.

Holck, A. L., Axelsson, L., Hünne, K. \& Kröckel, L. (1994). Purification and cloning of sakacin 674, a bacteriocin from Lactobacillus sake Lb674. FEMS Microbiol Lett 115, 143-150.

Holo, H., Nilssen, O. \& Nes, I. F. (1991). Lactococcin A, a new bacteriocin from Lactococcus lactis subsp. cremoris: isolation and characterization of the protein and its gene. $J$ Bacteriol 173, 3879-3887.

Hui, F. M. \& Morrison, D. A. (1991). Genetic transformation in 
Streptococcus pneumoniae: nucleotide sequence analysis shows $\operatorname{com} A$, a gene required for competence induction, to be a member of the bacterial ATP-dependent transport protein family. J Bacteriol 173, 372-381.

Hui, F. M., Zhou, L. \& Morrison, D. A. (1995). Competence for genetic transformation in Streptococcus pneumoniae: organization of a regulatory locus with homology to two lactococcin A secretion genes. Gene 153, 25-31.

Klaenhammer, T. R. (1993). Genetics of bacteriocins produced by lactic acid bacteria. FEMS Microbiol Rev 12, 39-86.

Klein, C., Kaletta, C. \& Entian, K. D. (1993). Biosynthesis of the lantibiotic subtilin is regulated by a histidine kinase/response regulator system. Appl Environ Microbiol 59, 296-303.

Kornblum J., Kreiswirth, B. N., Projan, S. J., Ross, H. \& Novick, R.P. (1990). agr: a polycistronic locus regulating exoprotein synthesis in Stapbylococcus aureus. In Molecular Biology of the Stapbylococci, pp. 373-402. Edited by R. P. Novick. New York: VCH.

Mackman, N., Nicaud, J. M., Gray, L. \& Holland, I. B. (1986). Secretion of haemolysin by Escberichia coli. Curr Top Microbiol Immunol 125, 159-181.

Marugg, J. D., Gonzalez, C. F., Kunka, B. S., Ledeboer, A. M., Pucci, M. J., Toonen, M. Y., Walker, S. A., Zoetmulder, L. C. M. \& Vandenbergh, P. A. (1992). Cloning, expression, and nucleotide sequence of genes involved in production of pediocin PA-1, a bacteriocin from Pediococcus acidilactici PAC1.0. Appl Environ Microbiol 58, 2360-2367.

van der Meer, J. R., Polman, J., Beerthuyzen, M. M., Siezen, R. J., Kuipers, O.P. \& de Vos, W. M. (1993). Characterization of the Lactococcus lactis nisin A operon genes nisP, encoding a subtilisinlike serine protease involved in precursor processing, and nis $R$, encoding a regulatory protein involved in nisin biosynthesis. $J$ Bacteriol 175, 2578-2588.

Nissen-Meyer, J., Larsen, A. G., Sletten, K., Daeschel, M. \& Nes, I. F. (1993). Purification and characterization of plantaricin $A$, a Lactobacillus plantarum bacteriocin whose activity depends on the action of two peptides. J Gen Microbiol 139, 1973-1978.

Parkinson, J. S. \& Kofoid, E. C. (1992). Communication modules in bacterial signaling proteins. Annu Rev Genet 26, 71-112.

Peng، H. L., Novick, R. P., Kreiswirth, B., Kornblum, J. \& Schlievert, P. (1988). Cloning, characterization, and sequencing of an accessory gene regulator (agr) in Stapbylococcus aureus. J Bacteriol 170, $4365-4372$.

Quadri, L. E. N., Sailer, M., Roy, K. L., Vederas, J. C. \& Stiles, M. E. (1994). Chemical and genetic characterization of bacteriocins produced by Carnobacterium piscicola LV17B. J Biol Chem 269, 12204-12211.

Quadri, L. E. N., Sailer, M., Terebiznik, M. R., Roy, K. L., Vederas,
J. C. \& Stiles, M. E. (1995). Characterization of the protein conferring immunity to the antimicrobial peptide carnobacteriocin B2 and expression of carnobacteriocins B2 and BM1.J Bacteriol 177, 1144-1151.

Sambrook, J., Fritsch, E. F. \& Maniatis, T. (1989). Molecular Cloning: a Laboratory Manual, 2nd edn. Cold Spring Harbor, NY: Cold Spring Harbor Laboratory.

Sanger, F., Nicklen, S. \& Coulson, A. R. (1977). DNA sequencing with chain-terminating inhibitors. Proc Natl Acad Sci USA 74, 5463-5467.

Schillinger, U. \& Lucke, F. K. (1989). Antibacterial activity of Lactobacillus sake isolated from meat. Appl Environ Microbiol 55, 1901-1906.

Schnell, N., Entian, K. D., Schneider, U., Gotz, F., Zăhner, H., Kellner, R. \& Jung, G. (1988). Prepeptide sequence of epidermin, a ribosomally synthesized antibiotic with four sulphide-rings. Nature 332, 276-278.

Stock, J. B., Ninfa, A. J. \& Stock, A. M. (1989). Protein phosphorylation and regulation of adaptive responses in bacteria. Micrabiol Rev 53, 450-490.

Stoddard, G. W., Petzel, J. P., van Belkum, M. J., Kok, J. \& McKay, L. L. (1992). Molecular analyses of the lactococcin A gene cluster from Lactococcus lactis subsp. lactis biovar diacetylactis WM4. Appl Environ Microbiol 58, 1952-1961.

Tichaczek, P. S., Nissen-Meyer, J., Nes, I. F., Vogel, R. F. \& Hammes, W. P. (1992). Characterization of the bacteriocins curvacin A from Lactobacillus curvatus LTH1174 and sakacin P from Lb. sake LTH 673. System Appl Microbiol 15, 460-468.

Tichaczek, P. S., Vogel, R. F. \& Hammes, W. P. (1994). Cloning and sequencing of sakP encoding sakacin $\mathrm{P}$, the bacteriocin produced by Lactobacillus sake LTH 673. Microbiology 140, 361-367.

Tínoco, I., Jr, Borer, P. N., Dengler, B. \& Levine, M. (1973). Improved estimation of secondary structure in ribonucleic acids. Nature 246, 40-41.

Vandenbergh, P. A. (1993). Lactic acid bacteria, their metabolic products and interference with microbial growth. FEMS Microbiol Rev 12, 221-238.

van der Vossen, J. M. B. M., van der Lelie, D. \& Venema, G. (1987). Isolation and characterization of Streptococcus cremoris Wg2specific promotors. Appl Environ Microbiol 53, 2452-2457.

Venema, K., Kok, J., Marugg, J. D., Toonen, M. Y., Ledeboer, A. M., Venema, G. \& Chikindas, M. L. (1995). Functional analysis of the pediocin operon of Pediococcus acidilactici PAC1.0: PedB is the immunity protein and PedD is the precursor processing enzyme. Mol Microbiol 17, 515-522.

Received 22 November 1995; revised 9 January 1996; accepted 15 January 1996. 